\title{
A TRANSMISSÃO, A CONSERVAÇÃO E A DIFU- SÃO DA CULTURA NO RIO DE JANEIRO (1808-1821) (II).
}

\author{
MARIA BEATRIZ NIZZA DA SILVA \\ do Departamento de História da Faculdade de Filo- \\ sofia, Letras e Ciências Humanas da Universidade \\ de São Paulo.
}

\section{2. - AS BIBLIOTECAS E SEU CONTEUDO.}

A importância do estudo do conteudo das bibliotecas para a história da cultura só ultimamente tem sido devidamente acentuada, em trabalhos como o de Daniel Ligou sobre a presença da obra romanesca em algumas bibliotecas francesas do século XVIII (1). E certo que já em 1910 Daniel Mornet abrira o caminho a tais pesquisas e que alguns estudos foram feitos sobre as bibliotecas de homens célebres, como Berkeley, Montesquieu e Diderot (2). O estudo das bibliotecas brasileiras dos tempos coloniais tambem já foi iniciado (3), mas o que convem acentuar é uma mudança de atitude em tais pesquisas.

(1). - "La part du roman dans quelques bibliothèques du XVIIIe siècle", in Roman et lumières au XVIIle siècle, Paris, 1970. O que mais chamou a nossa atenção neste trabalho foi a preocupação do autor com a presença ou ausência de um determinado gênero literário em bibliotecas de indivíduos pertencentes a grupos sociais diversos.

(2). - R. I. Aaron, "A catalogue of Berkeley's library", in Mind, XLI, 1932; Luis Desgraves, Catalogue de la bibliothèque de Montesquieu, Genebra, Lille, 1954; Jacques Proust, "La bibliothèque de Diderot", in Revue des sciences humaines, abril-junho de 1958 e outubro-dezembro de 1969.

(3) . - E. Bradford Burns, "The enlightenement in two colonial brazilian libraries", in Journal of the History of Ideas, 1964, vol. XXV, $\mathrm{n}^{\circ} 3$; Rubens Borba de Morais "Livros e bibliotecas no Brasil Colonial (1500-1808)" in Revista Interamericana de Bibliografia, vol. XXII, $\mathrm{n}^{\circ} 3,1972$; e o livro de Eduardo Frieiro $O$ diabo na livraria do cônego, Belo Horizonte, 1945. 
O estudo das bibliotecas do passado, públicas ou privadas, de homens célebres ou de desconhecidos, deve ser feito, não com a intenção de descobrir "influências" para a produção literária ou filosófica legada pelos grandes autores, ou com o fito de detectar o atraso ou o avanço de uma cultura em relação a outras culturas tomadas como modelo, mas sim o de delimitar áreas de interesse, o de analisar as opções culturais feitas e mesmo, graças aos catálogos sistemáticos, conhecer o sistema de classificação que numa dada sociedade presidia à ordenação da massa livresca.

Para o Rio de Janeiro do início do século passado, conseguimos obter apenas 2 catálogos, manuscritos, o primeiro de uma biblioteca institucional, a da Academia dos Guardas-Marinhas, e o outro de uma biblioteca particular, a de Antônio de Araujo de Azevedo, conde da Barca. Ambos os manuscritos se encontram conservados na Biblioteca Nacional. Nenhum catảlogo datado da Livraria Régia chegou até nós, mas quanto à composição, organização e público que frequentava esta b.blioteca, colhemos algumas informações na correspondência de Luís Joaquim dos Santos Marrocos, empregado que acompanhou a remessa de livros de Lisboa para o Rio de Janeiro em 1811, e tambem nos Estatutos da-Real Biblioteca, publicados pela Impressão Régia em 1821.

O estudo que faremos portanto da Livraria Régia não incide sobre o seu conteudo, porque não o conhecemos com exatidão, mas sim sobre outros aspectos, igualmente importantes em história da cultura: qual a concepção que o século XIX tinha de biblioteca, qual a sua organização e funcionamento, e que público atendia.

Em 1811, o serviço da Livraria Régia ocupava o Pe. Joaquim Damaso, Fr. Gregório José Viegas, Marrocos e outros três serventes, mas em 1814 o número de serventes subira para 6, embora muitos deles trabalhassem em outros lugares ao mesmo tempo (Marrocos, cartas 5 e 67). Os Estatutos de 1821 previam um prefeito, um ajudante, dois escreventes, e os serventes que fossem precisos $(\S 3)$.

Havia uma seç̧ão de manuscritos da qual Marrocos se encarregou logo em 1811, sendo este cargo por ele considerado de "segredo, importância e responsabilidade" (carta 6), tanto mais que sucedera a Fr. Antônio de Arrábida. Achou naquele Arquivo documentos preciosos, mas dos quais não era permitida cópia sendo só utilizado pelas esferas governamentais. Marrocos concebeu então o projeto de organizar esta massa documental: 
"Para prelúdio de meus trabalhos, e para dar a S. A. R. uma idéia do tesouro, que aqui possui nesta minha repartição, pertendo arranjar uma Memória literária e crítica deste mesmo corpo de manuscritos, pois que até aqui ainda se não sabe o que há, principalmente no que pertence ao governo político. No frontespício da dita Memória, ou no fim, hei-de ajuntar-lhe em forma de plano ou planta o sistema de classificação, que adotei para o arranjo dos mesmos livros, e julgo que não me arredei do trilho dos mestres bibliógrafos, ainda que foi sem socorro algum mais que mental" (carta 14).

Ignoramos se elaborou ou não esta Memória, mas se em história da cultura as intenções são tão importantes quanto os atos, temos aqui explicitada uma clara consciência arquivística, na qual se encontravam ao mesmo nivel, e portanto obedecendo ao mesmo sistema de classificação, os manuscritos e os impressos. Mesmo que não tenha elaborado a tal Memória, é natural que, enquanto trabalhou com os manuscritos, Marrocos os tenha de algum modo organizado. Em 1814 ainda estava encarregado deles:

"O meu exercício atual não é na Livraria, é sim no Real Tesouro, onde estão os manuscritos de que sou encarregado" (carta 71).

Em 1816, terminadas as obras na Livraria e mudando-se o Real Tesouro, Marrocos previa a incorporação dos manuscritos à biblioteca, mas na sua correspondência não dá notícia dessa incorporação se ter realmente verificado.

Quanto ao número de manuscritos, temos apenas uma referência do viajante Gustav Beyer que afirma ter a Biblioteca Real 4.000 manuscritos, além de 80.000 volumes (4).

Apesar de trabalhar principalmente com os manuscritos, Marro$\cos$ fornece-nos algumas informações sobre a Biblioteca Real e frequentemente opina sobre ela. Um problema que o preocupava ao chegar ao Brasil era o da catalogação, quer dos manuscritos quer dos livros, e por isso logo pediu para Lisboa

"uma cópia do sistema de classificação bibliográfica, feito pelo Dr. Antônio Ribeiro dos Santos para a Biblioteca pública",

(4). - Lemos a tradução portuguesa desta obra, publicada em Estocolmo em 1814, na Revista do Instituto Histórico e Geográfico de São Paulo, vol. XII, 1907: "Ligeiras notas de viagem do Rio de Janeiro à Capitania de São Paulo, no Brasil, no verão de 1813 ...", p. 278. 
explicando:

"são papelinhos aqui de muita estimação pois é terra de tudo esteril" (carta 9).

$\mathrm{Na}$ mesma carta conta que tinha sido incorporado à Biblioteca Real o espólio literário de Fr. José Mariano da Conceição Veloso,

"cousa de 2.500 volumes de livraria".

O núcleo de livros foi ainda aumentado devido a uma proposta de Marrocos:

"Com bem custo consegui dar-se para esta Biblioteca propina da Impressão Régia de tudo quanto se tem aqui impresso, e houver de imprimir-se, o que tenho por um passo muito vantajoso, a benefício desta casa" (carta 11).

Por outro lado, propôs Marrocos que se enviasse para a Bahia a grande quantidade de livros em duplicado que havia na Biblioteca Real do Rio. Mas só em 1818 se pôs em prática a sua idéia:

"Veio a verificar-se o meu projeto lembrado a princípio; pois Sua Magestade ordenou que dos livros dobrados da sua Real Biblioteca se fizesse fornecimento de um exemplar de cada obra para a Biblioteca Pública da Bahia, combinando-se estes com os do catálogo, que dali veio, de sorte que não viessem a duplicar-se, porem consistindo a remessa dos que ali não houvessem. Já para lá foram 20 caixotes, que somente compreendem o ramo de Teologia: e vai-se continuando" (5).

Mais tarde informa que já se tinham mandado para a Bahia 37 caixões de livros (cartas 130 e 132).

A instalação e a organização da Livraria Régia impediram que ela fosse imediatamente aberta ao público. Ignoramos a data exata em que ela começou a receber leitores; só podemos afirmar que foi depois de 1814 (carta 65), e que em 1819 ela estava toda classificada em grandes salas, sendo

"mui rica e respeitavel pelas importantes aquisições e compras" (carta 148).

(5). - O catálogo manuscrito dos livros da Bahia encontra-se na Biblioteca Nacional e foi por nós trabalhado. Ver Revista de História, n ${ }^{9} 87$ de 1971, "A Livraria Pública da Bahia em 1818: obras de História". O mesmo catálogo foi impresso na Bahia: Catálogo dos livros que se acham na Biblioteca Pública da Cidade da Bahia, s.1.n.d. (Bahia. Tipografia de M. A. da Silva Serva, 1818). 
Taunay e Denis, que se lhe referem, tambem não fornecem a data da abertura ao público, escrevendo apenas:

"Sa Magesté Très Fidèle a rendu publique sa bibliothèque composée de soixante mille volumes; on y entre depuis dix heures du matin jusqu'à quatre heures de l'après-midi, et l'on ne saurait trop se louer du zèle et de la complaisance des religieux qui en ont l'administration" (Le Brésil, cap. VII, p. 28-9).

Para o historiador da cultura que pretender fazer uma sociologia da leitura, constitui uma pesquisa básica o estudo do público que frequentava as bibliotecas, ou mesmo mais tarde os gabinetes de leitura (6). Simplesmente perguntas como estas: Quem frequentava a Livraria Régia? Que livros eram pedidos com maior frequência?, raramente encontram respostas. Quando muito temos informações fragmentárias. Marrocos, por exemplo, só nos diz que em 1812 o Marquês de Torres Novas era

$$
\text { "um dos assinantes fixos da Biblioteca" (Carta 18); }
$$

que o filho mais velho do visconde de Santarem, Manuel Francisco, era

$$
\begin{aligned}
& \text { "um moço assaz louvavel pelo seu estudo e aplicação pro. } \\
& \text { funda", }
\end{aligned}
$$

sendo dos que frequentavam a Livraria

"com a maior curiosidade e interesse literário" (carta 103);

que Silvestre Pinheiro Ferreira ia à Livraria com uma roda de discípulos atentos (Carta 98); que Strangford ficara com alguns livros da Biblioteca ("o Cancioneiro, e o Blasonero geral") e que Cipriano Ribeiro Freire, em Inglaterra, fora incumbido de

"sacar das unhas de Strangford os dous livros, pertencentes às Reais Bibliotecas, com que ele daqui saiu, abusando da franqueza de S. A. R. em lhos conceder, para os ler" (cartas 81 e 98).

(6). - Os historiadores franceses têm seguido essa orientação metodológica: ver por exemplo o artigo de Claude Pichois, "Les cabinets de lecture à Paris durant la première moitié du XIXe siècle", in Annales, julho-setembro, 1959. 
E é tudo o que conseguimos obter de Marrocos acerca dos leitores da Real Biblioteca.

Os Estatutos só indiretamente aludem ao tipo de frequentadores da Livraria Régia:

"O prefeito cuidará em que a Real Biblioteca esteja com toda a limpeza e arranjo possivel procurando corresponder com atenção, civilidade, e cortesania aos que têm faculdade, e procurarem a Real Biblioteca para se instruirem facilitando-lhes os livros que pedirem, e se thes puderem confiar conforme as leis tanto civis como eclesiásticas sobre a leitura dos livros" (\$11).

Por este parágrafo, e pelas referências de Marrocos, vemos que a Livraria Régia, muito embora estivesse aberta ao público, era quase exclusivamente frequentada por nobres, diplomatas, empregados públicos e outros que tinham faculdade, ou seja, que tinham permissão para o fazer.

Dado o preço de algumas obras e o escasso consumo de livros que se fazia no Rio de Janeiro do início do século XIX, a atividade de copiar por vezes obras inteiras era um hábito comum nos frequentadores da Biblioteca Real, e por tal razão um dos parágrafos dos Estatutos versa sobre a cópia de livros ou manuscritos (\$30). O próprio Marrocos, empregado na Livraria, fazia frequentemente cópia de textos para mandar para Portugal (7).

Só as pessoas da Família Real, ou então munidas de uma autorização especial, podiam retirar livros da Biblioteca, e quanto aos livros proibidos, que, segundo os Estatutos, seriam indicados num catálogo especial, ignoramos em que medida as proibições eram efetivamente cumpridas.

Quanto a outras bibliotecas, na carta régia de 4 de dezembro de 1810, que criou a Academia Real Militar, lemos:

"Logo que possa formar-se uma Biblioteca Científica e Militar para esta Academia, haverá um lente de História Militar, que servirá de Bibliotecário".

(7). - "Remeto tambem um papel, em forma de carta, por onde se colhe alguma notícia da viagem de S. A. R. a esta Corte; e ainda que o copiei à pressa V. Mce. entende bem a minha letra" (carta 7); "Eu estou copiando a história do casamento desta senhora, para remeter a V. Mce....." (carta 8). 
Ignoramos se tal biblioteca chegou a constituir-se, pois não encontramos nenhum catálogo dos seus livros, ao contrário do que aconteceu com a Biblioteca da Academia dos Guarda-Marinhas.

Conservado na Secção de Manuscritos da Biblioteca Nacional do Rio de Janeiro, o catálogo desta Biblioteca foi terminado em abril de 1812, muito embora uma nota acrescentada na última página tenha a data de 24 de julho do mesmo ano.

Trata-se de um catálogo "sistemático", mandado fazer pelo Inspetor da Companhia dos Guarda-Marinhas, e portanto importa referir o "sistema" nele adotado. Os livros e manuscritos foram distribuidos em 5 grandes divisões: I. - Ciências Naturais; II. - Ciências Matemáticas (puras e mistas); III. - Ciências e Artes Navais; IV. - Ciências e Artes Militares de terra; e V. - Polimatia. Cada uma destas divisões apresenta subdivisões, nas quais os livros e manuscritos estão arrolados cronologicamente, sendo indicados os nomes do autor, do editor e da obra, cujo título é sempre dado em português e de forma abreviada, e ainda se anotam as datas das edições e da morte do autor. Acerca desta última indicação, lemos o seguinte esclarecimento na nota introdutória do catálogo:

"Em quanto aos números escritos debaixo dos títulos "morte do autor' cumpre observar que deixamos em claro os correspondentes aqueles autores de quem não alcançamos conhecer com certeza o ano do falecimento e que pusemos 'vivo' nos que existiam ainda em o primeiro ano do século presente".

E dada ainda uma justificação para o critério cronológico adotado em cada subdivisão: destinava-se este a mostrar ao estudante "o progresso ou marcha do espírito humano" em cada área do saber.

O fato de existir este catálogo "sistemático", isto é, elaborado de acordo com um determinado sistema de classificação das ciências então existentes, não significa que a Biblioteca não possuisse outro tipo de catálogo:

"Para encontrar qualquer destas obras na Biblioteca, poder-se-á recorrer ao catálogo alfabético, mediante o nome do autor ou do editor, e mediante o da obra, se esta for de algum anônimo, ou de vários".

Dado que é impossivel transcrever aqui todo o catálogo, limitar-nos-emos a colocar os problemas metodológicos que surgiram na sua análise e a fazer algumas considerações sobre o seu conteudo. 
Quanto aos problemas metodológicos, o primeiro que tivemos de enfrentar foi o da tradução do título da obra para português, talvez para facilitar a utilização do catálogo por alunos pouco versados em línguas. Como não é indicado o lugar da edição, é impossivel saber com rigor a respeito de cada obra se se tratava da versão original, ou de uma tradução em outra língua, ou mesmo em português. Colocamos portanto imediatamente de lado uma pesquisa que tínhamos pensado fazer sobre a porcentagem dos vários idiomas nesta biblioteca, que podemos considerar ao mesmo tempo científica e especializada.

Não queremos com isto dizer que em alguns casos não fosse possivel determinar com certeza absoluta o exemplar possuido. Isso acontece quando é dado o nome do editor. Mas aqui cumpre explicar o que o autor do catálogo entendia por este termo: umas vezes era simplesmente o tradutor da obra, outras vezes era aquele que preparara uma edição póstuma. Vejamos um exemplo:

Autor: Desaguliers; Editor: Pezenas; título: Curso de Física; edição: 1751; morte do autor: 1773 . Com estes dados e com a ajuda dos Catálogos impressos da Biblioteca Nacional de Paris e da Biblioteca do Congresso foi possivel reconstituir com rigor a obra: John Theophilus Desaguliers, Cours de Physique expérimentale ... traduit de l'anglais par le R. P. Pezenas, Paris, 1751. O nome do editor, que aliás é indicado muito raramente, ajuda portanto de maneira eficaz a reconstituir o título exato da obra e consequentemente a conhecer em que língua ela constava na biblioteca.

O nome do autor era por vezes suficiente para reconstituir o título, mas apenas quando se tratava de um autor menos conhecido e cujas obras portanto não só tinham tido poucas edições na língua original como tambem não tinham sido traduzidas em línguas estrangeiras. Por exemplo: Lagny, Análise geral, 1733, morte 1734, foi facilmente localizado como Thomas Fantet de Lagny, Analyse générale, ou Méthodes nouvelles pour résoudre les problèmes de tous les genres et de tous les degrés, à l'infini, Paris, 1733. Mas tal localização era impraticavel em casos de autores como Lineu ou Gravesend, cujas obras foram editadas várias vezes não só em latim como em outros idiomas.

O que dificultava ainda mais a reconstituição do título da obra era a alta porcentagem de obras anônimas e de obras coletivas, sendo nestes casos inviavel qualquer tentativa de identificação. Por todas estas razões apenas podemos emitir um juizo precário sobre as obras contidas nesta biblioteca, do ponto de vista da língua: predominavam as obras escritas em francês, pois, mesmo quando se tratava de autores ingleses, era dada preferência à tradução francesa e não ao original. 
O segundo problema metodológico surgiu a propósito dos nomes dos autores. O catálogo só indicava o nome, nunca o prenome, o que dificulta a identificação de cientistas da mesma área e com obras semelhantes, como por exemplo o caso dos vários astrônomos de nome Cassini, ou os diversos viajantes de nome Mackensie ...

O terceiro problema metodológico resultou do laconismo na indicação do título da obra, por exemplo, Física experimental, Arte das experiências, Experiências sobre vegetäis, etc. Este laconismo é tanto mais desesperante para o pesquisador quanto no século XVIII, e mesmo no início do século XIX, estavam na moda os títulos longos, quase um índice dos assuntos tratados, os quais têm servido para interessantes pesquisas em história da cultura (8). Resolvemos portanto reconstituir os títulos completos de algumas centenas de obras e os nossos esforços foram recompensados, pois ficamos com uma noção muito mais correta do conteudo desta biblioteca, muito embora não tivéssemos lido, nem sequer manuseado muitos destes textos. Para dar alguns exemplos da diferença entre o título abreviado, e traduzido em português, e o título completo, escolhemos precisamente aqueles em que o contraste é mais gritante:

1. - Feuillée, Jornal de Física e Matemática, 1754 corresponde na verdade a Journal des observations physiques, mathématiques et botaniques faites par l'ordre du roi sur les côtes orientales de l'Amérique méridionale et dans les Indes occidentales depuis l'année 1707 jusqu'en 1712 (Introduction aux tables des mouvements du soleil. Tables des mouvements du soleil. Histoire des plantes médicinales qui sont le plus en usage aux royaumes de l'Amérique méridionale, du Pérou et du Chily).

2. - Gruson, Pinacoteca, 1798: trata-se de Pinacothèque, ou collection de tables d'une utilité générale pour multiplier et diviser, inventées par Jean-Philippe Gruson.

3. - Ingenhousz, Experiências sobre os vegetais, 1780: é a obra Expériences sur les végétaux, spécialement sur la propriété qu'ils possèdent à un haut degré, soit d'améliorer l'air quand ils sont au soleil, soit de le corrompre la nuit, ou lorsqu'ils sont à l'ombre.

(8). - Ver Jean-Louis Flandrin, "Sentiments et civilisation. Sondage au niveau des titres d'ouvrages", in Annales, set.-out., 1965; e F. Furet e A. Fontana no artigo "Histoire et linguistique. Les titres d'ouvrages au XVIIIe siècle", publicado na revista Langages (setembro de 1966) e desenvolvido em Livre et société dans la France du XVIIle siècle, Paris, 1970. 
Feitas estas observações metodológicas preliminares, podemos passar à análise do conteudo desta biblioteca, advertindo contudo que deixamos de lado o estudo dos manuscritos e que só trataremos das obras. Vejamos a primeira grande divisão: Ciências Naturais.

Incluia esta seç̧ão obras de Botânica, Química e História Natural, Física (principalmente "a eletricidade, o galvanismo, o magnetismo e a metereologia"). Não se pode dizer que constituisse o núcleo central de uma biblioteca destinada a Guardas Marinhas, mas apesar disso contam-se 39 títulos, excluindo os "polígrafos", como escreve o autor do catálogo. Se não computamos estes é porque os seus nomes, ainda mais do que os dos outros autores, são repetidos em várias secçōes, o que perturba o cálculo.

Um dos aspectos importantes a focar numa biblioteca científica, sobretudo se se trata de uma livraria destinada a estudantes, é a sua atualização e podemos dizer que, dos autores citados, os mais antigos, mas que como clássicos da ciência tinham de fazer parte obrigatoriamente de uma biblioteca científica, eram Jacques Rohault, físico célebre do século de Luís XIV e Lineu. Muitos ainda se encontravam vivos no início do século XIX: Jean-Antoine-Claude Chaptal, abade René-Just Haüy, Antoine-François Fourcroy, Jan Ingenhousz, George Adams o novo, Mathurin-Jacques Brisson, P. Aimé-Henri Paulian.

Havia nesta seç̧ão obras muito elementares como as do $\mathbf{P}$. Louis Cotte (9), obras de referência como o Dictionnaire de Physique de Paulian, e obras de sucesso como as do abade Nollet sobre a eletricidade (10), mas a maioria era constituida por tratados gerais, compostos com objetivos didáticos embora de nivel elevado.

Apenas 2 autores portugueses nesta secção: o naturalista Félix Avelar Brotero, com o seu Compêndio de Botânica, e Sarmento, autor de uma Teórica das marés. Quanto aos outros autores estavam representados do seguinte modo: P. Louis Cotte, 4 obras; Lineu, 7; Chaptal, 1; Haüy, 1; Fourcroy, 1; Rohault, 1; Roger Cotes, 1; Gravesend, 1; Desaguliers, 1; abade Nollet, 5; Le Monnier, 1; abade Para du Phanjas, 2; Jan Ingenhousz, 2; Brisson, 2; George Adams, o novo, 3; Saussure, 1; Pierre Prévost, 1; Duhamel du Monceau, 1; Paulian, 1. Havia uma única obra de autor anônimo.

(9). - Leçons élémentaires d'Histoire Naturelle par demandes et réponses, à l'usage des enfants (1784) e Leçons élémentaires d'Histoire Naturelle d l'usage des jeunes gens (1787).

(10). - Lettres sur l'éloctricité (1764), Recherches sur les causes particultères des phénomènes électriques et sur les effets nuisibles qu'on peut en attendre (1764), Essai sur l'électricité des corps (1765). 
A II divisão, intitulada Ciências Matemáticas (puras e mistas) é a de maior peso na biblioteca, até porque inclui numerosas subdivisões: Aritmética e Âlgebra, Cálculo superior, Geometria e Trigonometria, Astronomia, Mecânica, Ótica . A respeito desta divisão o autor do catálogo esclarecia que incluia na Álgebra

“a sua aplicação à Aritmética e à Geometria, tanto a inferior como a transcendente"

e que o mesmo fizera em relação ao Cálculo. Dizia ainda que incluira na Mecânica

"a Hidroestática, a Hidrodinâmica, com as suas aplicações à construção de pontes, diques, etc. e a Relojoaria",

e na Ótica,

"a Perspectiva, o Desenho, e os fenômenos relativos à marcha da luz".

São tantas as obras e os autores desta divisão que não é possivel fazer uma referência circunstanciada a todos eles, como fizemos para a divisão anterior. Sem contar os numerosos polígrafos, são aproximadamente 150 títulos (é dificil dar o número certo porque, como dissemos, muitas obras são referidas simultaneamente em várias subdivisões), alem de 7 obras anônimas e 7 obras coletivas. Na Aritmética e na Álgebra aparecem nomes célebres (Condorcet, Euler, Legendre, Lagrange, Condillac, Clairaut) ao lado de autores menos conhecidos como Fantet de Lagny, Reyneau, Colin Mac Laurin, Mazéas, Bezout, Prony, Mauduit, Cousin, Gruson, Reishammer. No Cálculo superior, alem de alguns autores já citados, Hôpital, Carnot, Bossut. Na Geometria e Trigonometria, encontramos a edição mais antiga desta biblioteca, uma Geometria de Euclides editada em 1534, alem das obras de dois autores do século de Luís XIV, Jacques Ozanam e o abade Picard. Mas a maior parte dos autores desta subdivisão eram modernos e nota-se pela primeira vez a presença de italianos, mas em versão francesa: Cagnoli, Lorenzo Mascheroni. A Astronomia é dominada pelos dois Cassini (Jean Dominique Cassini, César-François Cassini, conhecido como Cassini de Thury), por Laplace, Le Monnier, Clairaut, Flamsteed, e um autor alemão Johann Elert Bode, autor de uma Uranografia em latim, e de uma descrição das constelações em edição bilíngue, alemão-francês. A Mecânica conta com Belidor, d'Alembert, Berthoud, Berthelot, Bossut, Marie, Carnot, Monge, Lagrange, Prony. $\mathrm{Na}$ Ótica, destacam-se La Caille, Newton. 
A III divisão, Ciências e Artes Navais constitui o núcleo específico da biblioteca da Academia dos Guardas Marinhas e nela se incluem as seguintes subdivisões: Arquitetura naval, Cordoaria, Instalação e Manobras, Geografia e Hidrografia, Pilotagem, Tática Telegráfica e Governo Militar Náutico. Na Instalação inseria-se

"a arrumação e o detalhe das coisas e pessoas";

na Tática

"a Telegrafia, ou tudo o que respeita aos sinais".

Dado que esta divisão é que atribui um carater especializado a esta biblioteca, parece-nos mais importante aqui citar alguns títulos de obras, daqueles que conseguimos. reconstituir, do que prendermo-nos a autores, na sua maior parte desconhecidos para o leitor não especialista em Ciências e Artes Navais: Traité du navire, de sa construction et de ses mouvements, de Bouguer, 1746; Scientia navalis seu tractatus de construendis ac dirigendis navibus, de Euler, 1749; Eléments d'architecture navale, ou Traité pratique de la construction des vaisseaux, de Duhamel du Monceau, 1758; De la manoeuvre des vaisseaux, ou Traité de mécanique et de dynamique dans lequel on réduit à des solutions très simples les problèmes de marine les plus difficiles, qui ont pour objet le mouvement du navire, de Bouguer, 1757; Traité de la fabrique des manoeuvres pour les vaisseaux, ou de l'art de la corderie perfectionné, de Duhamel du Monceau, 1769; Le manoeuvrier, ou Essai sur la théorie et la pratique des mouvements du navire et des évolutions navales, de Bourdé de Villehuet, 1769; Reflexiones sobre las maquinas y maniobras del uso de á bordo, ordenadas por Francisco Ciscar, 1791; Traité pratique du gréement des vaisseaux et autres bâtiments de mer, de Lescallier, 1791; Manuel des marins, ou Dictionnaire des termes de Marine, de Bourdé de Villehuet, 1773; L'Art de la Marine, ou Principes et préceptes généraux de l'art de construire, d'armer, de manoeuvrer et de conduire des vaisseaux, de Romme, 1787; Geographia ó moderna descripcion del mundo, enriquezida de cartas geographicas y de algunas relaciones de los países orientales, de Sebastian Fernández de Medrano, 1726; Analyse géographique de l'Italie, de Bourguignos d'Anville, 1744, etc.

Citamos apenas estas obras como exemplo, pois a lista seria demasiado longa se transcrevêssemos todos os títulos de manuais, tratados, artes de navegar, roteiros, que compunham a biblioteca das Guardas Marinhas. E interessante que nesta livraria, predominantemente náutica, se encontrem tambem livros referentes às Ciências e Artes militares de terra. 
Compõem esta IV divisão as seguintes subdivisões: Artilharia e Cavalaria, Engenharia e Infantaria, Tática e Governo Militar, observando o autor do catálogo que na Artilharia se incluia

$$
\text { "os artifícios de fogo, ou a Pirotecnia", }
$$

e na Engenharia

"a Castrometação, a Fortificação de campanha e a permanente, o ataque e defesa das províncias e o relativo a estradas, principalmente as militares".

Desta divisão constam os tratados clássicos do português José Fernandes Pinto Alpoim: Exame de Artilheiros que compreende Aritmética, Geometria, e Artilharia (1744) e Exame de Bombeiros, que compreende dez tratados; o primeiro da Geometria, o segundo de uma nova Trigonometria, o terceiro de Longimetria, o quarto de Altimetria, o quinto dos morteiros, o sexto dos pedreiros, o sétimo do obus, o oitavo dos petardos, o nono das baterias dos morteiros, o décimo da Pirobolia (1748). E os textos do conde de Lippe: Regulamento para o exercício, e disciplina, dos Regimentos de Infantaria dos Exércitos de Sua Magestade Fidelissima (1763) e as Direções que hão de servir para os .... coroneis, tenentes coroneis, e majores dos Regimentos de Infantaria dos Exércitos de Sua Magestade Fidelissima executarem com precisão os grandes movimentos das tropas (1767).

Esta divisão conta cerca de 60 títulos, abundando os textos anônimos, e como sempre, muitos se encontram inseridos em outras divisões, dado o carater essencialmente didático deste catálogo. Muitos textos de História militar, por exemplo, constam tambem da $\mathrm{V}$ e última divisão, intitulada Polimatia.

Nesta última divisão inserem-se as obras de História, Literatura, Viagens, Miscelânea impressa, esclarecendo o autor do catálogo que a Literatura incluia

"os conhecimentos gramaticais, poliglotas e retóricos, com alguns filosóficos"

e a Miscelânea

"o concernente às Artes, Ofícios, Higiene marítima, Cirurgia, Medicina, Comércio, Direito, Diplomacia, etc.".

Na subdivisão História os autores portugueses estão bem representados numericamente, ao contrário do que acontecia nas outras 
subdivisões: contam-se 12 historiadores, entre os quais estão Damião de Gois, Francisco de Andrade, João de Barros, Garcia de Resende, Duarte Nunes de Leão, Jacinto Freire de Andrade, etc. Não podiam faltar aqui as Histórias navais, como a de Thomas Lediard em versão francesa, Histoire navale d'Angleterre, depuis la conquête des Normands, en 1066, jusqu'à la fin de l'année 1734 (1751), a obra de Robert Beatson Naval and military memoirs of Great Britain, from 1727 to 1783 (1802), o livro de Isaac Schomberg, Naval chronology; or, An historical summary of naval and maritime events, from the time of the Romans, to the treaty of peace, 1802. With an apendix (1802); ou as biografias de marinheiros célebres, por exemplo, a versão francesa do livro de Andrew Kippis, Vie du capitaine Cook (1789), ou a coletânea de Adrien Richer, Vie des plus célèbres marins. Embora em número menor, constam algumas Histórias militares ou biografias de militares, por exemplo, a obra de Dumont, ampliada por Rousset de Missy, Histoire militaire du prince Eugène de Savoie, du prince et duc de Malborough, et du prince de Nassau-Frise (1735), a versão francesa do livro de Andrew Michael Ramsay, Histoire du vicomte de Turenne, maréchal général des armées du Roi (1735), a obra do cavaleiro de Beaurain, Histoire de la campagne de $M$. le prince de Condé en Frandre en 1674, précédée d'un tableau historique de la guerre de Hollande jusqu'à cette époque (1774), a obra do conde de Grimoard, Tableau historique et militaire de la et du règne de Frédéric le Grand, roi de Prusse (1788). Havia ainda a obra de referência indispensavel em qualquer biblioteca de então: Le grand dictionnaire historique, ou le Mélange curieux de l'histoire sacrée et profane de Louis Moreri (1759).

Como seria de esperar numa biblioteca destinada a Guardas Marinhas e como aliás o próprio autor do catálogo explicou, a subjivisão Literatura inclui apenas alguns dicionários e gramáticas e alguns textos de teor filosófico: as obras do abade Para du Phanjas, Théorie des êtres insensibles, ou Cours complet de metaphysique sacrée et profane, mise à la portée de tout le monde (1779) e Eléments de Métaphysique sacrée et profane, ou Abrégé du cours complet de métaphysique et de la philosophie de la religion (1780); o livro de Alexandre Savérien, Histoire des progrès de l'esprit humain dans les sciences naturelles et dans les arts qui en dépendent... avec un abrégé de la vie des plus célèbres auteurs dans ces sciences (1775); e ainda Oeuvres posthumes de d'Alembert, publicadas por Pougens em 1799.

Na subdivisão Miscelânea convem chamar a atenção para obras de carater prático, relacionadas com a vida do mar: a versão francesa do livro de Stephen Hales, Instructions pour les mariniers, contenant la manière de rendre l'eau de mer potable; de conserver l'eau douce, le 
biscuit, le bled; et de saler les animaux (1740); a obra de Duhamel du Monceau, Moyens de conserver la santé aux équipages des vaisseaux, avec la manière de purifier lair des salles des hôpitaux, et une courte description de l'hôpital Saint-Louis, à Paris. (1759); o livro então recente de William Turnbull, The naval surgeon comprising the entire duties of professional men at sea. To which are subjoined, a system of naval surgery, and a compendious pharmacopeia (1806). Havia ainda obras de Direito Marítimo: a tradução espanhola do livro do inglês Charles Molloy, Derecho maritimo y naval, ó Tratado de los negocios maritimos y del comercio (1793), e o livro de Dominique Albert Azuni, Droit maritime de l'Europe (1801).

Naturalmente a biblioteca da Academia dos Guardas Marinhas possuia uma coleção notavel de relatos de viajantes, que são referidos simultaneamente na subdivisão Geografia da III divisão e na subdivisão Viagens, da V divisão. Referiremos apenas alguns, chamando a atenção para o interesse que despertavam as viagens em geral, e não apenas para aquelas regiões onde os portugueses tinham domínios.

Entre esses relatos de viagem contam-se: a tradução francesa do original alemão, Relation du voyage d'Adam Olearius en Moscovie, Tartarie et Perse, augmentée en cette nouvelle édition. . . d'une seconde partie contenant le voyage de Jean Albert de Mandelslo aux Indes Orientales (1659); a tradução francesa do original holandês, Voyage de Gautier Schouten aux Indes orientales, commencé l'an 1658, et fini lan 1665 (1725); a obra do P. Labat, Voyage du chevalier Des Marchais en Guinée, îles voisines, et à Cayenne, fait en 1725, 1726 et 1727 (1730); o texto atribuido ao abade de Choisy, Journal du voyage de Siam fait en 1685 et 1686, par M.L.D.C. (1741); a versão francesa do original espanhol, Voyage historique de l'Amérique méridionale fait par ordre du roi d'Espagne par don George Juan... et par don Antoine de Ulloa... qui contient une histoire des Yncas du Pérou, et les Observations astronomiques et physiques, faites pour déterminer la figure et la grandeur de la Terre (1752); o relato de Chabert, Voyage fait par ordre du roi en 1750 et 1751 dans l'Amérique septentrionale, pour rectifier les cartes des côtes de l'Acadie, de l'île-Royale et de l'île de Terre-Neuve, et pour en fixer les principaux points par les observations astronomiques (1753); o texto escrito por Paul Boyer, escudeiro, senhor de Petit Puy, Véritable relation de tout ce qui s'est fait et passé au voyage que Monsieur de Bretigny fit à l'Amérique occidentale. Avec une description des moeurs, et des provinces de tous les sauvages de cette grande partie de Cap Nord: un dictionnaire de la langue et un avis très nécessaire à tous ceux qui veulent habiter ou faire habiter ce pays-là, ou qui désirent d'y établir des colonies (1754); a versão francesa do texto inglês de John Henry Grose, 
Voyage aux Indes orientales (1758); a versão francesa da obra Voyage autour du monde fait en 1764 et 1765, sur le vaisseau de guerra anglais Le Dauphin, commandé par le chef d'escadre Byron (1767); a tradução francesa do original alemão de Gmelin, Voyage en Sibérie, contenant la description des moeurs et usages des peuples de ce pays (1767), alem de muitos outros relatos de viagens, que seria demasiado longo transcrever. blioteca?

Que conclusões podemos tirar da análise do conteudo desta bi-

Em primeiro lugar, podemos considera-la uma "livraria" atualiza$d a$ : se excetuarmos Euclides, a maior parte dos autores pertencia ao século XVIII, havendo 84 que ainda estavam vivos no início do século XIX. Se contarmos os autores do século XVII, eles são em número muito reduzido, concentrando-se em áreas onde a atualizaçăo não era um elemento importante: História e Viagens. Quanto à parte científica, os autores mais antigos são Jacques Rohault, Jacques Ozanam, Newton.

Observamos depois que se tratava de uma biblioteca especializada e concentrada, ou seja, os alunos da Academia dos Guardas Marinhas encontravam nela os textos necessários às matérias que estudavam, e não possuiam obras a mais, isto é, de áreas não relevantes para o seu aprendizado. Daí o escasso número de obras na secção de Literatura, e mesmo assim nesta só se incluiam dicionários, gramáticas, textos filosófico-científicos, e nenhum livro de poesia, nenhuma tragédia ou comédia, nenhum conto ou novela. Os alunos tinham à sua disposição aproximadamente 48 títulos em Ciências naturais, 194 títulos em Ciências matemáticas, 200 em Ciências e Artes Navais, 70 em Ciência e artes miltiares de terra, 138 na Polimatia.

Em terceiro lugar constatamos que era uma biblioteca predominantemente francesa, quer pelos autores quer pelos tradutores. $\mathrm{E}$ que os autores nacionais, em número reduzido, se concentravam na área de História e na de técnicas militares ou náuticas: contamos apenas 33 autores portugueses, dos quais cumpre salientar José Fernandes Pinto Alpoim, Manuel do Espírito Santo Limpo, José Melitão da Mata, Francisco de Paula Travassos, autores de obras técnicas.

O historiador da cultura jamais consegue fazer a história que idealizou porque aqueles documentos básicos para responder às suas questões, ou não existem, ou são difíceis de encontrar, requerendo anos e anos de pesquisa para a sua localização. Os inventários de bens constituem a pista principal para a descoberta das bibliotecas particulares, mas ficamos decepcionados quando, compulsando o inventá- 
rio de um dos mais ricos negociantes do Rio de Janeiro, Elias Antônio Lopes, senhor de 100 escravos, de várias casas e com um palácio em construção, possuidor de jóias e trajos riquíssimos, encontramos inventariadas apenas 18 obras:

"Um Dicionário português e francês; um Magnum Lexicon; seis Seletas latinas; uma Partícula Latina Oratório; uma Arte de gramática; dois P. Virgilio Maronis; um Novo Método; um Ano Meditativo; um Perfeito pedagogo; um Obrigação dos amos e criados; um Visitas de Smo. Sacramento; um Modo de assistir à missa" (Arquivo Nacional, Cod. 789, fol. 27-28).

A avaliação de todos os seus livros somava apenas a quantia de $12 \$ 500$ réis. Sabemos por outro lado que o Intendente da Polícia possuia uma

"copiosa, e escolhida Livraria",

mas não encontramos vestígios dela (18). A Gazeta do Rio de Janeiro trazia por vezes avisos de venda de bibliotecas, mas sem revelar o nome dos seus possuidores nem indicar o seu conteudo: esclarecia apenas de que gênero de biblioteca se tratava. Vejamos o seguinte aviso:

"Quem quiser comprar uma livraria, que se compõe unicamente de livros próprios para qualquer advogado, ou magistrado, dirija-se à rua da Alfândega, e na casa $n^{\circ} 40$ do lado direito tratará da compra com a pessoa encarregada da dita livraria" (n 99,1809$)$.

Outras vezes o aviso não trazia claramente a palavra livraria; falava apenas de uma "coleção de livros", expressão ambígua porque não nos dá a certeza de se tratar efetivamente de uma biblioteca particular, embora o contexto pareça indica-lo:

"Em Matacavalos n" 11, se acha uma coleção de livros de Medicina, Cirurgia, Matéria Médica, Química, etc., latinos, franceses e ingleses, que se vendem muito baratos, ou todos, ou às

(11). - Na dedicatória a Paulo Fernandes Viana, escreve o vigário Eduardo José de Moira: "V. S. alem dos benefícios, que me tem feito, os maiores, que se podem esperar, fez-me o de me franquear desde o princípio da minha carreira oratória a sua copiosa, e escolhida Livraria (...) inspirando-me o gosto da boa literatura, e até ensinando-me a folhear os nossos clássicos antigos". (Oração, que no dia 22 de janeiro de 1809 recitou Eduardo José de Moira) 
obras, e mesmo se trocam por outros de diferentes matérias" ( $\mathrm{n}^{\circ}$ 20, 1819).

Trata-se portanto de uma coleção de livros especializados, que não interessavam a quem os tinha (certamente não era o seu proprietário original). A pessoa queria ver-se livre deles, vendendo-os a baixo preço ou mesmo trocando-os por obras para ela mais interessantes. Outro aviso é redigido nos seguintes termos:

"Na rua Direita $\mathrm{n}$ \% 53, perto da rua dos Pescadores, se acha exposta à venda uma excelente coleção de livros franceses, italianos, e latinos, composta dos melhores autores em Poesia, Oratória, História, e Cirurgia. As pessoas, que quiserem comprar junta ou separada a dita coleção, aí se podem dirigir das 8 horas da manhã até às 2 da tarde" (n 2,1819$)$.

John Luccock assistiu no Rio de Janeiro a uma venda de livros e fez o seguinte comentário sobre os gostos literários da sociedade letrada carioca:

"In 1818, at a sale of books, English works went off well, as did some Latin ones; but few, I believe, fell into Brazilian hands. French books are in demand; but it was impossible, by any means, to sell the Glasgow edition of Homer's Iliad, in greek; the Septuagint and New Testament in the same language, Hederic's nor even Schrevelius's Lexicons; nor did a Hebrew Psalter, with a Latin translation, find a customer" (Notes, p. 574-5).

Quando Luccock diz que poucos livros foram comprados por brasileiros, ele está ou não excluindo os portugueses? Cremos que sim, pelo menos aqueles portugueses mais recentemente estabelecidos no Rio de Janeiro e portanto conservando ainda os seus hábitos de leitura metropolitanos. A procura de livros franceses, a saida facil de livros ingleses e mesmo latinos (basta lembrar que se liam ainda muitas obras médicas do século anterior escritas em latim), a dificuldade de escoamento de obras de pura erudição, eis alguns depoimentos interessantes sobre o leilão de livros no Rio de Janeiro.

$\mathrm{E}$ isto nos faz compreender que ninguem tenha arrematado a mais rica biblioteca particular então posta à venda: a do conde da Barca, cujo catálogo manuscrito nos irá ocupar mais demoradamente, por se tratar de um documento precioso para o historiador da cultura.

Em 1818, depois da morte do conde da Barca, Antônio de Araujo de Azevedo, foi elaborado um catálogo da sua biblioteca. O manus- 
crito encontra-se na Biblioteca Nacional e ao estuda-lo verificamos tratar-se de um catálogo extremamente bem feito, no qual as obras se encontram corretamente descritas, com a data e local da edição, número de volumes, formato, tipo de apresentação (encadernado, brochado, em papel) alem do preço por que seriam leiloadas. Mas ainda em abril de 1819 o testamenteiro e herdeiro beneficiário do conde da Barca, livraria"

"achando truncadas muitas obras, que existiam completas na

e notando

"uma grande falta de estampas e mapas",

por meio de um anúncio na Gazeta do Rio de Janeiro (n⿳28) rogava a sua restituição a todas as pessoas que,

$$
\text { "por esquecimento, ou qualquer outro motivo", }
$$

as conservassem em seu poder.

A livraria do Conde da Barca era constituida na sua maior parte por livros em francês (786), logo seguidos pelas obras em inglês (413) e em latim (404), vindo os livros em português apenas em quarto lugar com 299 títulos. O alemão, o espanhol e o italiano equivaliam-se $(167,130,108)$ e surpreendeu-nos o número relativamente elevado de obras em holandês (60) . O resto era constituido por edições bilíngues e um ou outro exemplar em russo, grego ou sueco.

Havendo no Catálogo 5 grandes divisões (Teologia, Jurisprudência, Ciências e Artes, Belas Letras e História), por sua vez subdivididas, notamos que o latim é a língua predominante nas obras de História Natural, e o francês e o inglês dominam a área de História, que incluia Geografia e Viagens. O holandês aparece insistentemente nas subdivisões de Ótica e Mecânica.

Foram postos à venda 2.418 títulos, avaliados num total de 15:599\$900 rs. Muitos deles tinham um preço extremamente baixo, principalmente os folhetos, vendidos até por 40 réis. Quando se tratava de uma obra ricamente encadernada, o catálogo fazia menção especial, mas são poucos os livros nestas condições. Ficamos surpreendidos com o número avultado de brochuras na biblioteca deste nobre e ignoramos o significado da indicação em papel que aparece à frente de alguns títulos. 
O conde possuia por vezes vários exemplares de um mesmo folheto, por exemplo, tinha 7 exemplares das Considérations importantes sur l'abolition générale de la traite des nègres (Paris, 1814) e do Secours contre les incendies, por M. Tréchard (s.1.n.d.). O título era contudo contado uma única vez, só sendo repetido quando se tratava de edições diferentes da mesma obra. Acontece muito excepcionalmente o mesmo folheto ser indicado no Catálogo dentro de uma divisão e depois aparecer tambem no Apêndice, como observamos com Mémoires sur les prétendus émigrés savoisiens (s.1., 1796), indicado no no 1835 e no no 2408 .

Como introdução ao estudo desta importante biblioteca, parece-nos util referir o modo como foi paulatinamente constituida, servindo-nos para isso da correspondência inédita entre Silvestre Pinheiro Ferreira, encarregado de negócios em Berlim, e Antônio de Araujo de Azevedo, ministro dos Estrangeiros e da Guerra, em 1804 (12).

Silvestre Pinheiro Ferreira recebia em Berlim pedidos de livros por parte de Antônio de Araujo e portanto podemos afirmar que algumas das obras leiloadas no Rio de Janeiro em 1818 tinham sido adquiridas por intermédio daquele funcionário:

"Os livros aqui comprados para V. Exa. teriam partido logo que recebi a carta de V. Exa., se o encadernador, pretextando falta de marroquim, me não tivesse retardado as obras de Wieland. Mas enfim estão prontas e partirão dentro de poucos dias" (carta de 12 de outubro de 1804).

Pela mesma carta vemos que Silvestre Pinheiro Ferreira não atendia apenas aos pedidos de livros, mas tambem de estampas:

"Envio incluso um resumo do catálogo das estampas que formam a colcção de Brena. Pede 28.000 escudos (ou 45\$500 cruzados pouco mais ou menos). E provavel que a deixe por 25\$000: o que vem a ser a razão de 12 grossos (ou 325 rs) por estampa. Das outras curiosidades que não têm catálogo, nem pode fixar o preço enquanto o não fizer: do que porem não está longe, uma vez que veja probabilidade de as vender".

E antes de terminar a carta, escrevia ainda:

(12) - Na nossa tese de doutoramento sobre o pensamento de Silvestre Pinheiro Ferreira, só publicamos alguns excertos destas cartas, principalmente aqueles que continham dados biográficos, deixando inédito um material assaz vasto. 
"Espero qualquer dia resposta de Francfort sobre a coleção de estampas de Bartolozzi; logo que a receba, a transmitirei a V. Exa.".

Simplesmente, enquanto os livros eram comprados a título particular, as estampas eram negociadas por vezes a título oficial.

Alguns dias mais tarde voltava a escrever:

"O correio passado tive a honra de remeter a V. Exa. um resumo do Catálogo da coleção de estampas que Brena pretende vender e pela qual pede $28 \$ 000$ escudos em último preço (pouco mais ou menos 42 mil cruzados). Hoje remeto outro catálogo e juntamente a carta que Mettra, livreiro desta cidade, me dirigiu, para que V. Exa. possa ajuizar se a coleção, que ele pretende vender, corresponde ao objeto que V. Exa. se tem proposto. Esslinger (que assim se chama o dono da coleção de estampas de Bartolozzi) me escreveu prometendo-me resposta circunstanciada sobre os quesitos que lhe dirigira a respeito da dita coleção. Para o seguinte correio espero poder satisfazer a V. Exa. neste particular" (carta de 20 de outubro de 1804).

A carta do livreiro berlinense era a seguinte:

"Monsieur

D'après les détails dans lesquels vous avez eu la bonté d'entrer vis à vis de moi, c'est avec une franchise desinteressée que je crois pouvoir vous présenter ma collection d'estampes anciennes comme entièrement propre à remplir l'objet qu'on se propose. On peut la regarder comme complète à l'égard des maîtres, et si l'on veut l'enrichir c'est un cadre où l'on placera d'abord en son lieu tout ce que l'on y voudra joindre.

J'ai travaillé depuis vingt années à former cette collection unique peut-être en considérant la rareté des pièces du premier âge qu'il a fallu se procurer, le travail nécessaire pour leur vérification exacte, l'arrangement chronologique et le bon choix des pièces des $17 \mathrm{e}$ et $18 \mathrm{e}$ siècle. Mon amour paternel pour cette collection est tel que je n'ai cessé de l'augmenter successivement au point que, sans m'en appercevoir, elle se trouve maintenant de plus de 20 mille feuilles, sans que j'aie pensé à augmenter le prix que j'ai fixé sur le calcul seul de mes dépenses, lorquelle n'en contenait que 18.000 .

En voici, Monsieur, le relevé général par apperçu; il a été fait à la hâte, comme vous l'avez exigé, de manière qu'il n'a été noté qu'une bien faible partie des feuilles remarquables. 
Des circonstances domestiques me déterminant à me séparer de cet enfant chéri, je serai dedomagé par la certitude que cette collection reste entière, et se trouve consacrée au genre d'utilité que j'ai eu en vue en y travailiant.

Les objets d'art ayant repris leur valeur depuis que les temps qui leur étaient contraires sont changés, je suis convaincu que les feuilles séparées, dans la vente publique la plus malheureuse produiraient plus que le double du prix dont je me contente pour la totalité et qui est irrevocablement fixé à trois mille frédérics d'or, faisant de 33 à 34.000 marcs de banque de Hambourg.

Il vous sera facile de reconnaitre l'extrême modicité de cette demande par le tableau suivant.

Réduction des véritables prix de chaque feuille pour rendre en masse et ne comptant pour rien les soins qu'à exigé ce complettement.

300 - feuilles de 4 à 15 fréderics d'or. On les compte au plus de ce prix 1.200

1.200 - de 1 à 4 fréd. d'or. estimées à 1 fréd. d'or 1.200

4.000 - audessus d'un fréd. d'or, à moitié $\quad \mathbf{2 . 0 0 0}$

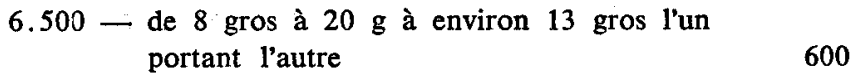

8.600 - valant d'un $1 / 2$ gros à $1 / 3$ d'écu

fréd. d'or 5.000 gratis, pour mémoire

20.600 feuilles

Je suis avec respect

Monsieur

Votre très humble et très

obéissant serviteur

Berlin, le 148 bre 1804

\section{Mettra".}

Numa carta sem data, Silvestre Pinheiro Ferreira esclarece que as obras de Wieland e mais livros tinham sido adquiridos por mil escudos, e comunica:

"por ora não se oferece aqui leilão notavel",

o que parece indicar que algumas das obras que compõem a livraria do conde de Barca eram adquiridas em leilóes e não diretamente aos livreiros. Esta hipótese é confirmada pela enumeração, no catálogo da 
sua biblioteca, de vários catálogos de livros postos à venda por morte dos seus possuidores: Chrétien Guillaume Lamoignon Malberbes ( $\mathrm{Pa}-$ ris, 1797), Marquês Saint-Simon (Utrecht, 1799), cidadão Le Brun (Paris, 1798), Duque de la Vallière (Paris, 1783), Abraham Martins (Haia, 1798), cidadão Amelot (Paris, 1797), Messire H. Fagel (Haia, 1792), Marconnay (Berlim, 1800), G. Swartendyk (Haia, 1796), François van der Hopp (Haia, 1794), Arnaut Vormaer (1800). Pelas datas destes catálogos de bibliotecas particulares possuidos pelo conde da Barca, vemos que eles pertencem exatamente ao período em que Antônio de Araujo mais viajou pela Europa, antes de se tornar secretário de Estado em 1804. Durante os anos itinerantes, ele próprio se interessava pelos leilões de livros; depois de 1804, residente em Lisboa, era através de Silvestre Pinheiro Ferreira em Berlim, e certamente através de outros funcionários diplomáticos nas principais capitais européias, que ele tomava conhecimento de tais leilōes e fazia as suas compras. escreve:

Na carta de 30 de outubro de 1804, Silvestre Pinheiro Ferreira

"Tenho a honra de remeter inclusa a lista das estampas de Bartolozzi, que Esslinger me acaba de remeter de Francfort: e juntamente outra das obras de Angélica Kauffmann, que Madame Krayen de Leipzig, informada por Esslinger da carta que eu lhe escrevera, me mandou oferecer pelo preço que vai declarado no fim da mesma lista". E um pouco mais adiante: "Os livros de V. Exa. partiram para Hamburgo, donde espero que sejam expedidos sem perda de tempo".

Embora residindo em Freiberg em 1805, Silvestre Pinheiro Ferreira ocupava-se ainda dos interesses culturais de Antônio de Araujo:

"Supondo que V. Exa. terá sem dúvida recebido o catálogo da coleção de estampas, que o livreiro Mettra de Berlim expôs em venda, devo informar a $\mathrm{V}$. Exa., que tendo ele falecido pelos fins de novembro, acabo de receber uma carta da viuva que desejava saber, se eu já tinha recebido resposta do meu constituinte a respeito da dita coleção; porque tanto ela como os outros herdeiros se vêem na precisão de realizar quanto antes a herança, para poderem satisfazer aos muitos encargos, com que se acha pensionada. Tambem do Professor Huber, filho do que V. Exa. conheceu em Leipzig, recebi um catálogo manuscrito da coleção que herdou de seu pai. Sendo demasiado volumoso para ir pelo correio, esperarei ocasião de navio para o comunicar a V. Exa." (carta de 18 de janeiro de 1805). 
Alguns meses mais tarde informava:

"a coleção de Huber acaba de ser comprada pelo duque de Gotha por $8 \$ 000$ florins" (carta de 15 de abril de 1805).

\section{Novamente em Berlim comunica:}

"Segundo o que V. Exa. me determinou a respeito dos seus livros, escrevo a Schubach para que os expresse com a coleção de minerais, comprada em Freiberg, a fim de gozarem dos passaportes que a devem acompanhar" (carta de 29 de maio de 1805).

Em fins de 1805 enviou Silvestre Pinheiro Ferreira uma nova remessa de livros a Antônio de Araujo, prevenindo:

“ $\mathrm{Na}$ lista do encadernador que encaixotou os que remeti ultimamente em cinco caixas não encontro várias obras, que o livreiro diz ter fornecido. Para tirar toda a dúvida, sirva-se $\mathrm{V}$. Exa. ordenar à pessoa que cuida da sua livraria me remeta uma contra-nota à que eu remeti a V. Exa. apontando-me nela os livros não recebidos ou não notados na minha" (carta de 19 de novembro de 1805).

O negócio das estampas de Bartolozzi, artista de grande sucesso em Portugal, parecia resolvido em 1806:

"Escrevi a Francfort prometendo pela coleção de estampas de Bartolozzi 300 fredericos: e Esslinger não só aceitou a proposição, mas me escreve que passava imediatamente a expedi-las. Espero que este preço muito inferior ao de 300 Las st. pelo qual a dita coleção se reputava aí não ser cara, mereça a aprovação V. Exa. Para o pagamento fiz uso do crédito que V. Exa. se serviu de me mandar abrir na casa de Godeffroy Filho e Compa em Hamburgo, por ser a promessa do pronto pagamento que decidiu Esslinger no atual aperto em que se acham por aquelas partes. A coleção de Brena já partiu há muito para Itália, onde ele espera ter mais ocasião de a vender. Retive-a quanto pude; mas, consultando durante a minha ausência, ao nosso ministro, este lhe respondeu, segundo ele diz, que as finanças do Reino nos não permitiam entrar em semelhantes compras. Contudo se aí se resolver o fazer esta aquisição, poderá igualmente fazer-se em Itália. A de Mettra ainda existe, e creio que pedem por ela e pela livraria $40 \$ 000$ cruzados" (carta de 10 de março de 1806). 
As estampas de Bartolozzi chegaram a Berlim pouco tempo depois e a 8 de abril Silvestre Pinheiro Ferreira anunciava:

"depois de amanhã começarei a examina-las com assistência de pessoa entendida e professora, cujo voto não possa ser suspeito";

caso não fossem exatamente como tinham sido anunciadas, a transação seria desfeita. Foi o que efetivamente aconteceu, como se pode ver pela carta de 24 de junho, pois, ajudado por dois célebres professores de Berlim, Frick e Freidhof, Silvestre Pinheiro Ferreira chegou à conclusão de que os 300 fredericos eram um preço excessivo:

"Uma grande parte das estampas são mal conservadas, poucas antes da letra; e não há quase nenhuma que seja em bom papel, com boa margem e sem defeito essencial".

O catálogo da biblioteca do Conde da Barca só enumera os livros e ignoramos se existe um outro catálogo das estampas e mapas. De qualquer forma, o modo de constituição destas bibliotecas e coleções era muito semelhante: através de leilőes.

Antes de fornecermos o número de títulos por divisão e subdivisão do catálogo, convem chamar a atenção para um fato. Na subdivisão História Literária estava incluida uma série de obras em francês intituladas Bibliothèques e que devem ser encaradas como uma espécie de antologias das várias literaturas. A Encyclopédie de Diderot e D'Alembert esclarece-nos aliás acerca da moda destas coletâneas no verbete Bibliothèque:

"Quelques auteurs ont donné, par extension et par métaphore, le nom de bibliothèque à certains recueils qu'ils ont faits, ou à certaines compilations d'ouvrages. Telles sont la bibliothèque rabbinique, la bibliothèque des auteurs ecclésiastiques, bibliotheca patrum, etc.".

Uma das mais célebres coletâneas do século XVIII, que se encontra no catálogo do conde, é a Bibliothèque universelle de Jean Le Clerc (1657-1736), imitação da République des Lettres de Bayle, segundo Voltaire, que preferia este último. $O$ conde possuia ainda uma Bibliothèque anglaise em 15 volumes (Amsterdão, 1727), uma Bibliothèque française em 42 volumes (Amsterdão, 1746), uma Bibliothèque choisie, da autoria tambem de Jean Leclerc, em 28 volumes (Amsterdão, 1712), do mesmo autor uma Bibliothèque ancienne et moderne em 29 volumes (Haia, 1730), uma Bibliothèque germanique em 25 volumes (Amsterdão, 1720), uma Nouvelle Bibliothèque ger- 
manique em 26 volumes (Amsterdão, 1746) e uma Bibliothèque britanique em 25 volumes (Amsterdão, 1733).

A existência destas "bibliotecas" levanta um problema metodológico na medida em que seria necessário inquirir o seu conteudo antes de emitir juizos de valor sobre a livraria do conde. Muitos autores e muitas obras podem estar omissos nas respectivas divisões, mas constarem daquelas coletâneas, assaz amplas como vimos pela média dos volumes.

Teologia.

Número de

Textos, e versões da Escritura Sagrada

Titulos

Teólogos, e Moralistas

5

Catecismos, e Oraçốes

12

Teologia Mística, ou Contemplativa

2

Orações Sagradas

Teologia Polêmica

Teologia Heterodoxa.

Jurisprudência .

Direito Canônico

Direito Eclesiástico Português

Direito Civil, da Natureza, e das Gentes, e Direito Público

Dịreito Pátrio

Legislação estrangeira: Espanha

França

Inglaterra

Alemanha

Nápoles

Holanda .

Ciencias e Artes.

Filosofia

Etica, ou Moral

Economia $\quad 12$

Política $\quad 21$

Comércio, e Finanças 33

História Natural: História Natural em geral $\quad 34$

História Natural dos Elementos 6

Mineralogia $\quad 12$

Metalurgia $\quad 2$

História Natural dos Fóssiles, e das Petrificações $\quad 16$

História Natural das Pedras 
História Natural das Águas, Banhos e Águas Minerais 3

Agricultura e Jardinagem 25

Botânica $\quad 106$

História Natural dos Animais $\quad 30$

História Natural dos Animais Anfíbios 2

História Natural dos Peixes $\quad 7$

História Natural das Conchas $\quad 17$

História Natural dos Insetos do Rio e de Terras 2

História Geral dos Insetos $\quad 30$

História Natural dos Monstros, Prodígios, etc. 1

Gabinetes, ou Coleções de Curiosidades da Natureza,

Medicina $\quad 43$

Anatomia $\quad 2$

Medicina Veterinária 1

Física em geral 33

Química $\quad 30$

Matemática $\quad 29$

Astronomia $\quad 24$

Astrologia 1

Hidrografia $\quad 11$

Otica e Perspectiva 2

Música $\quad 2$

Mecânica $\quad 24$

Artes $\quad 15$

Arte do Desenho, e Pintura 17

Arquitetura $\quad 8$

Arquitetura Militar 3

Arte Militar $\quad 12$

Arte Pirotécnica, ou do Fogo, da Fundição, etc. 5

Ginástica $\quad \cdot 2$

Artes, e Ofícios Mecânicos 3

Belas Letras. 5

Gramáticas, e Dicionários $\quad 38$

Retórica: $\quad 6$

Oradores Gregos $\quad 7$

Oradores Latinos 14

Poética. 3

Poetas Gregos $\quad 41$

Poetas Latinos 105

Poetas Latinos de Nações Estrangeiras 8

Poetas Portugueses $\quad 42$

Poetas Espanhois $\quad 15$ 
Poetas Franceses $\quad 16$

Poetas Ingleses $\quad 28$

Poetas Italianos 39

Poetas Alemães $\quad 10$

Teatro. 5

Teatro Grego 15

Teatro Latino 14

Teatro Português 10

Teatro Espanhol 8

Teatro Francês $\quad 17$

Teatro Inglês 23

Teatro Italiano 19

Teatro Alemão 4

Mitologia. $\quad 4$

Fábulas, Apólogos, etc. 9

Facécias, Peças Burlescas, etc. 5

Contos e Novelas 3

Romances $\quad 15$

Filologia.

Tratados de Estudo, e de Literatura 15

Crítica 2

Sátiras, Invectivas, Defensas, Apologias 7

Adágios, Provérbios, etc. 1

Discursos Filológicos, Críticos, Alegóricos 1

Poligrafia:

Diálogos e Entretenimentos 6

$\begin{array}{ll}\text { Coleções de Cartas } & 5 \\ \text { História. } & 2\end{array}$

Geografia em geral $\quad 39$

Viagens em geral $\quad 101$

Cronologia 3

História Universal 52

História Eclesiástica $\quad 25$

História dos judeus 9

História geral das 4 monarquias antigas, dos Caldeus, Babilônios, etc. 6

Historia Grega $\quad 14$

História Romana $\quad 35$

História de Portugal 36

História de Espanha $\quad 46$ 


\begin{tabular}{lr} 
História de França & 85 \\
História de Inglaterra & 73 \\
História da Alemanha & 10 \\
História da Prússia & 8 \\
História da Itália & 10 \\
História da Holanda & 19 \\
História da Suiça & 4 \\
História da Suécia & 4 \\
História da Polônia & 3 \\
História da Rússia & 11 \\
História Oriental: História dos Turcos & 3 \\
História da Ásia & 16 \\
História de África & 12 \\
História da América & 6 \\
História dos Estados Unidos da América & 8 \\
História Genealógica & 1 \\
História Política ou Diplomática & 26 \\
Antiguidades: Museus, Pedras, Gravados, Inscrições, & \\
\multicolumn{1}{c}{ Numismática } & 47 \\
História Literária & 146 \\
Vida dos Homens Ilustres & 12 \\
Apêndice no 1. & 361
\end{tabular}

Através deste índice vemos que a livraria do conde da Barca continha: 38 obras de Teologia, 78 de Jurisprudência, 695 de Ciências e Artes, 598 de Belas Letras e 868 de História, alem de um Apêndice de 361 títulos. Ignoramos a razão que levou o autor do catálogo a elaborar este Apêndice, mas podemos levantar uma hipótese: vimos que o herdeiro e testamenteiro do conde, solicitou, através de um aviso na Gazeta, a restituição de muitas obras que tinham sido emprestadas, sendo plausivel portanto que neste Apêndice constem alguns livros restituidos depois da elaboração do catálogo. De qualquer modo, dado que o número de títulos é bastante elevado, podendo portanto alterar o panorama geral que apresentamos, convem determo-nos um pouco nessa lista e, tentando classificar as obras de acordo com o critério do catalogador, ver se há uma diferença sensivel naquela distribuição. Usando como amostra apenas as obras francesas e portuguesas, mais numerosas no Apêndice, 48 seriam inseridas na História, 22 nas Ciências e Artes, 9 nas Belas Letras, 1 na Jurisprudência, e 3 na Teologia, ou seja as relações entre as respectivas áreas manter-se-iam aproximadamente as mesmas.

Ao contrário da biblioteca institucional, especializada e concentrada, esta biblioteca particular, pertencente a um nobre que alem de 
literato (13) ocupou cargos na burocracia da época, revela um leque de interesses extremamente amplo e variado. E manifesto contudo o menor peso da Teologia e Jurisprudência, e o maior peso da História explica-se, não só pela inclusão da Geografia e da Literatura de viagens, mas tambem porque muito textos que hoje qualificaríamos de políticos estavam nela incluídos. Isto nos faz afirmar que nos gostos do conde da Barca 3 áreas tinham sensivelmente o mesmo estatuto, enquanto duas outras existiam a título de simples curiosidade erudita.

(13). - Inocêncio Francisco da Silva atribui-lhe a tradução da Ode de Dryden para o dia de Santa Cecília, a tradução da Elegia de Gray composta no cemitério de uma igreja de aldeia, uma "Memória em defesa de Camões contra Mr. de la Harpe", e uma tragédia Osmia. 